\title{
VASPITNO-OBRAZOVNA FUNKCIJA RADIJA U PERIODU OD 1929. DO 1940. GODINE U KRALJEVINI JUGOSLAVIJI ${ }^{* *}$
}

Apstrakt: Radio je prvi elektronski medij masovnog komuniciranja čija je struktura u tehničko-tehnološkom smislu konačno oformljena u prvim decenijama 20. veka, čime su omogućeni uslovi da se njime masovno distribuiraju auditivne poruke $\mathrm{u}$ oblikovanim radio programima. Svakako najznačajnija imena koja su doprinela razvoju radija su: Nikola Tesla, Guglielmo Marconi, Lee De Forest i drugi istraživači. Razvoj medija masovne komunikacije doveo je do velikih i trajnih kulturnih promena koje su se odrazile i na promene u vaspitanju. Kao pedagozi, svesni smo koliku moć imaju mediji i da su upravo mediji ti koji su umnogome promenili ponašanje dece i roditelja u odnosu na prethodne generacije. Period od 1929. do 1940. predstavlja period kada razvoj radija kao masovnog medija doživljava svoju ekspanziju, kako u svetu, tako i u Kraljevini Jugoslaviji, gde je radio program pokrenut 24. marta 1929. u Beogradu. U ovom radu dati su rezultati do kojih se došlo analizom obimnog programskog sadržaja emitovanog na Radio Beogradu u periodu od 1929. do 1940. u Kraljevini Jugoslaviji. Pored navedenog, posebna pažnja posvećena je utvrđivanju vaspitno-obrazovnih funkcija koje je radio imao u navedenom periodu.

Ključne reči: vaspitno-obrazovna funkcija, Radio Beograd, Kraljevina Jugoslavija, program za decu i mlade, Nacionalni čas.

\section{UVOD}

Mediji masovnih komunikacija predstavljaju široku oblast kojom se bavi mnoštvo naučnih disciplina a mogu da se analiziraju sa različitih

\footnotetext{
*Branislava Bjelić, branislava2402994@gmail.com

** Rad predstavlja rezultate master rada nastalog na master akademskim studijama pedagogije na Filozofskom fakultetu u Beogradu.
} 
stanovišta, ali i iz različitih razloga. Istraživanje odnosa radija kao sredstva masovnog komuniciranja i obrazovanja i vaspitanja podrazumeva najmanje tri aspekta $\mathrm{s}$ kojih se taj odnos mora posmatrati: pedagoško-psihološki, sociokulturni i medijski. Pedagoška nauka mora da sagleda sva tri aspekta, jer svaki od njih ima uticaj na decu i mlade. Radio na različite načine utiče na ljude. Jedan od tih uticaja jeste saznajni: mediji utiču na naše znanje tako što u našu svest ugrađuju različite ideje i informacije - svakim novim korišćenjem dobijamo nove (Poter, 2008:150). Zatim, radio utiče na formiranje stavova, ima emocionalni uticaj, utiče na ponašanje dece i odraslih (Poter, 2011: 151-153). Predmet ovog istraživanja su vaspitno-obrazovne funkcije radija u periodu od 1929. do 1940. u Kraljevini Jugoslaviji. Kada je reč o cilju istraživanja, on podrazumeva utvrđivanje vaspitno-obrazovnih funkcija radija u periodu od 1929. do 1940. u Kraljevini Jugoslaviji.

Tokom istraživanja i traganja za definicijom moglo se naići na celokupan rečnik izraza, a ono što je ključno jeste da sve definicije u svojoj raznolikosti ukazuju na krajnji cilj medija i to je - komunikacija. Za potrebe ovog rada, upotrebljena je sledeća definicija radija: prvi elektronski medij masovnog komuniciranja kojeg odlikuju: neposrednost, mogućnost prenošenja informacija širokom auditorijumu, auditivni sadržaji, mogućnost prenošenja događaja u trenutku dešavanja i postojanje „pozorišnog uma“.

Vaspitno-obrazovne funkcije podrazumevaju da se mediji koriste radi učenja i saznavanja u okviru kojih se stiču znanja, umenja i navike, zatim da razvijaju sposobnosti, utiču na formiranje ličnosti individue (Antonijević, 2013) i da ,prenose kulturne sadržaje s jedne generacije na drugu čime povećavaju društvenu koheziju, proširuju društvene norme i nastavljaju socijalizaciju” (Jurčić, 2017:131). Kada se govori o obrazovnoj funkciji, 
podrazumevaju se opšta znanja koja se prenose putem medija, a „ona mogu imati poseban obrazovni karakter preko specijaliziranih obrazovnih programa koji se bave naukom, istraživanjem i popularizacijom“ (Jurčić, 2017:130). Postoje i druge funkcije koje je radio kao masovni medij imao a biće spominjane u radu. Neke od tih funkcija su: informacija, integracija, socijalizacija i vođstvo, zabava, kao i selekcijska i interpretacijska funkcija (Jurčić, 2017, 130-131).

Radio Beograd je izdavao časopis pod naslovom Radio Beograd $\mathrm{u}$ kojem su objavljivani prilozi i radijski program. Sadržaj tog časopisa je osnovni izvor za proučavanje ovde zadate teme. Časopis je izlazio periodično u periodu 1929-1940; objavljeno je ukupno 590 brojeva. U maloj redakciji časopisa Radio Beograd kao novinar radio je Slobodan Glumac koji je pisao kratke tekstove o značajnim emisijama, kompozitorima, dirigentima, muzičkim ansamblima, autorima i izvođačima radio-drama (Boarov, Barović, 2011: 275). Pored navedenog, Slobodan Glumac je prevodio prigodne tekstove o radio-emisijama iz sličnih namenskih revija koje su izdavale evropske radio-stanice (ibidem).

Metoda koja je korišćena za proučavanje teme rada jeste istorijska metoda. Za potrebe programske sheme konstruisane su evidencione liste uz pomoć kojih su beležene kategorije radijskog programa i utvrdivane frekvencije različitih kategorija. Prikupljeni podaci obrađeni su kvalitativno i kvantitativno. Kvantitativnim putem utvrđene su kategorije nalažene $\mathrm{u}$ radijskom programu, potom njihova zastupljenost $\mathrm{u}$ odnosu na program $\mathrm{u}$ celini i dinamika njihovog javljanja. Prilikom kvalitativne obrade podataka radijskog programa, korišćeni su opisi sadržaja izvora. 


\section{Vaspitno-obrazovni sadržaji u ukupnom programu Radio Beograda}

U tekstu koji sledi prikazan je ukupan sadržaj programa emitovanog na Radio Beogradu u periodu od 1929. do 1940. u Kraljevini Jugoslaviji; sledi njegovo grafičko prikazivanje i objašnjavanje programa koji su se pojavili tokom analize. Ukupan program Radio Beograda koji je emitovan može se podeliti u dve kategorije: muzičko-zabavni sadržaj (69\%) i govorni $\operatorname{sadržaj}^{1}(31 \%)$.

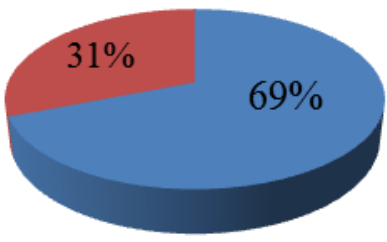

- Muzičko-zabavni sadržaj

- Govorni sadržaj

\section{Grafikon 1. Radio formati u programu Radio Beograda}

\footnotetext{
${ }^{1}$ Autori koji se bave problematikom radija nisu saglasni u pogledu terminologije kada je u pitanju podela radijskog programa. Kada je reč o muzičkim sadržajima, veliki broj autora je saglasan sa tim pojmom i koristi ga uz male korekcije (na primer: muzičko-zabavni program; muzički program i sl). Teškoća se javlja prilikom izbora pojma za sadržaj koji se emtiuje na radiju a ne spada u muzički sadržaj. Na primer, Bulatović i saradnici (1979) ukupan program Radio Beograda dele na muzički i govorni program, a govorni program dele na poučni, zabavni i informativni. Nikola Marinčić u svom radu $O$ producentskom radiju ili novinarskom radiju ukazuje da se radio formati mogu podeliti u tri grupe: muzički format radija (MFR), govorno-muzički (MOR) i govorni format (N/T) (Maričić, 2007: 167-168). Pojedini autori ga imenuju kao „ne-muzički“, „ostali sadržaj“ i sl. Uzimajući u obzir raznovrsnost koja se javlja kada je u pitanju podela radijskog programa, za potrebe ovog istraživanja i pisanja rada načinjene su određene korekcije u nazivima.
} 
Muzičko-zabavni sadržaj

Od prvog dana kada je radio stanica počela sa radom, urednici radijskog programa smatrali su da muzika treba da zauzima važno mesto $u$ muzičkom programu jer je - kao važan zadatak - postavljeno predstavljanje jugoslovenske kulture kako stranim tako i domaćim potrošačima, ali, pre svega, jačanje nacionalnonog identiteta Jugoslovena (Vesić, 2013:35-36). Posebno isticanje muzičkih sadržaja u radijskom programu bilo je regulisano i Pravilnikom iz 1933. godine; u Članu br. 5 piše: „u programima radiostanica biće u prvom redu zastupljena muzika, i to: nacionalna i slovenska, zatim ona strana koja će pravilno i zdravo razvijati muzički ukus“ (1933:358). Urednici su uočili doprinos muzike u vaspitanju dece i mladih, a to je da muzika utiče na razvoj dece, posebno na emocionalni razvoj, da popravlja raspoloženje, doprinosi razvoju kreativnosti i drugo.

U ovom se radu neće detaljnije razmatrati muzičko-zabavni sadržaji emitovani na Radio Beogradu iako su i ovi sadržaji doprinosili jednim delom vaspitanju i obrazovanju dece i mladih. Pre svega, za analizu tog dela programa potrebno je odgovarajuće muzičko obrazovanje, kao i mogućnost da se čuje celokupan muzičko-zabavni sadržaj emitovan na radiju.

Govorni sadržaj

Analizom programske sheme Radio Beograda, ustanovljeno je da oko 1/3 programa pripada govornom sadržaju. Kategorija govorni sadržaj je veoma raznovrsna. Tematskom analizom programa identifikovane su i imenovale izvesne kategorije. Zastupljenost pojedinih kategorija u okviru govornog sadržaja prikazana je na Grafikonu 2. 
Potrebno je napomenti da kategorija „kultura/umetnost/književnost“ ne postoji pod takvim nazivom u programskoj shemi. Tokom analize programa, objedinjeni su sadržaji koji pripadaju ovoj grupi pod jednim imenom radi bolje pregledenosti podataka. Zastupljenost ovog programa na radijskom programu je $16 \%$ i sastoji se od: čitanja poznatih dela, prenosa iz Narodnog pozorišta, monologa, emisija za inostranstvo, izvođenja poznatih dela, šetnje kroz Evropu, novela, prenosa ton-filma, šahovskih izveštaja, recitacionog časa, humorističkih dijaloga, radio tišine, šetnje kroz Beograd, radio kozerije, učenja Korana, nedeljnog političkog pregleda, časa humora i humorističnih novina.

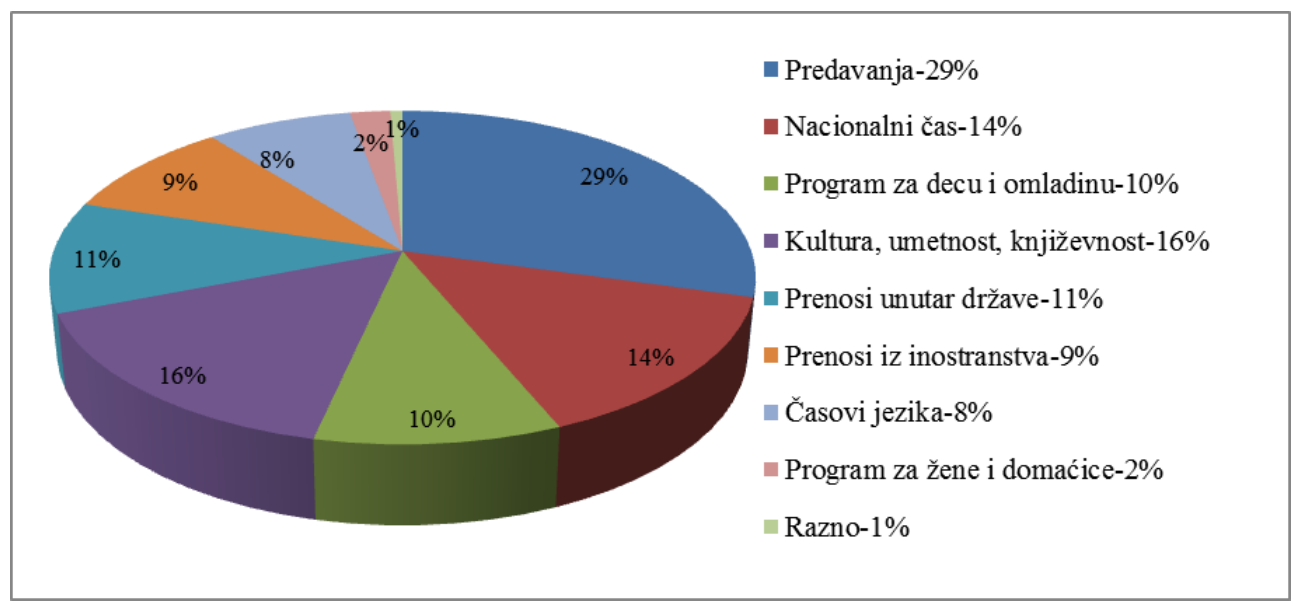

Grafikon 2. Govorni sadržaj na Radio Beogradu

Kategorija „prenosi unutar države“ obuhvata prenose manifestacija: informativnih, sportskih (prvi sportski radio prenos utakmice BSKJugoslavija), kulturnih, političkih dešavanja, poseta političara, obeležavanja važnih datuma i praznika - zastupljenost $11 \%$ sadržaja. 
„Prenosi iz inostranstva“ čine 9\% zastupljenosti i obuhvataju prenose iz različitih država. To su, pre svega, prenosi kulturno-umetničkih programa, posebno koncerata i opera, sportska dešavanja, posete važnih državnika, obeležavanje bitnih datuma i drugo.

„Program za žene i domaćice" sastoji se od praktičnih saveta i uputstva iz kuzmetike Nade Kujundžić, časova univerzitetski obrazovanih žena, časa za žene i časa za domaćice.

Kategorija „razno“ sastoji se od časa za seljake i časa narodnog zdravlja sa $1 \%$ zastupljenosti. Naziv "razno" nastao je tokom analize podataka jer ova dva časa nisu mogla da pripadnu nekoj od navedenih kategorija programa.

Programi sa vaspitno-obrazovnim sadržajem

Iz Grafikona 2 vidi se da 61\% govornog sadržaja čine vaspitnoobrazovne kategorije. Ovi su programi izdvojeni zbog njihovih naglašenih vaspitno-obrazovnih namera i razmatrani su uzimajući u obzir prethodno usvojenu definiciju, kao i zakonsku regulativu kojom su definisane vaspitnoobrazovne funkcije radija.

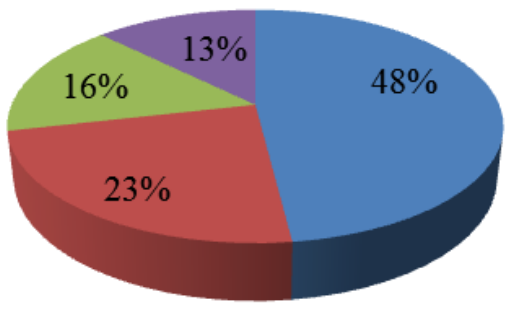

- Predavanja

- Nacionalni čas

- Program za decu i mlade

n Časovi jezika

Grafikon 3. Radijski program vaspitno-obrazovnih sadržaja 


\section{Programi za decu i mlade}

Program za decu i mlade obuhvata sledeće: čas za decu, koncerte učenika muzičke škole, Filips-dečije podne, čas za đake, čas gimnastike za decu, pesničko veče najmlađih, šareno veče, radio žurnal za decu, interpretacioni čas, čas podmladka Crvenog krsta, štivo za decu i omladinski čas.

C̆as za decu se u radijskom programu nalazio pod još dva naziva: „Tetka Mica Bandić čita priče“ i „Bajke za decu“; emitovale su se uživo uz postojanje mogućnosti da deca budu deo programa. Čas za decu označava same početke dečjeg radijskog programa. Književnost ima veoma važnu ulogu u životu i razvoju dece jer je među prvim umetnostima sa kojima se deca susreću još u najranijem detinjstvu (Stojanović Đorđević i Ilić, 2017:3). Bajka je čudesno lepa priča o čudesnom (Trebješanin, 2013:28). Jedna od glavnih funkcija koju bajka preuzima na sebe jeste ta da nauči dete da se spoljašnji svet razlikuje od njegove zajednice u kojoj raste, da ga pripremi za život u spoljašnjem svetu gde postoje razne opasnosti sa kojima može da se suoči (Stojanović Đorđević i Ilić, 2017:6). Zato u bajci uvek postoji stalna borba između dobra i zla u kojoj na kraju pobedu odnosi dobro. Bajka je prvi korak ka moralnom obrazovanju deteta (Betelhajm, 2015:11; prema: Stojanović Đorđević i Ilić, 2017:5).

Važno je da bajke na brojne načine utiču na različita područja dečijeg razvoja. U području socio-emocionalnog razvoja, uz razvijanje empatije kroz uživljavanje u različite uloge, deca uče da uočavaju, razumeju i izražavaju različita osećanja (Graša, 2016:15). Takođe, zahvaljujući bajkama, imaju mogućnost da izraze svoja osećanja i pričaju o njima sa odraslima. Kada se govori o motoričkom razvoju, deca mogu da kroz scenu iz bajke odigraju 
pokretnu igru, da govor sinhronizuju sa pokretima ruku i nogu, čime se podstiče razvoj fine motorike. Nakon čitanja bajke, razgovor sa decom može ih podstaći na komentare i rasprave, čime razvijaju sposobnosti komunikacije, kritičkog mišljenja i konstruktivnog rešavanja sličnih situacija u stvarnom životu (Graša, 2016:5). Svakako, bajke pomažu jezičko-govorne aktivnosti, razvoj govora, način pravilnog izražavanja, proširivanje vokabulara, pravilno izgovaranje glasova i drugo (Graša, 2016:5).

Pored Časa za decu, na Radio Beogradu emitovani su i koncerti učenika muzičkih škola; učenici su u školama mogli da slušaju prenose tih koncerata i izvođenja poznatih dela. Korišćenjem radija u školama - gde je imao funkciju pomoćnog nastavnog sredstva u okviru nastave muzičke kulture - učenici su imali priliku da se upoznaju sa osnovnim pojmovima teorije muzike, istorije muzike i muzičkim instrumentima (Vesić, 2016:643-645). Važno je da je ove koncerte mogla da sluša auditorijum cele Kraljevine Jugoslavije. Pored navedenih emisija postojala je i emisija pod nazivom Čas za đake.

U nekim emisijama učestvovali su đaci osnovnih škola kojima je čas i bio namenjen. Kasnije se javljaju i časovi za učenike srednjih škola u kojima se daju dramske skice i prilozi iz omladinske književnosti i ti časovi traju 45 minuta (Bulatović i saradnici, 1979:148). Posmatrajući navedene emisije, uočava se uvažavanje dečije perspektive - deca su uključivana u radijski program i pružena im je mogućnost za aktivno učešće u radijskom programu. U počecima razvoja masovnih medija deca se izdvajaju kao posebna vrsta medijske publike. 
Pesničko veče najmlađih, Šareno veče, Interpretacioni čas i Filipsdečije podne - emisije emitovane na Radio Beoradu - podrazumevale su izvođenje poznatih dela, slušanje muzičkih dela sa gramofonskih ploča, operske izvedbe, recitovanje.

Radio žurnal za decu emitovan je povremeno na programu Radija u periodu od 1933. do 1936. obuhvatavši Dnevnik za decu i mlade, dok su Interpretacioni čas (1934) i Štivo za decu (1938) trajali samo godinu dana a emitovali su vaspitno-obrazovni sadržaj. Navedeni sadržaji javljali su se retko u programskoj shemi. Analiza priloga u časopisu Radio Beograd ne omogućuje detaljnije objašnjenje programskih sadržaja. Na ovom mestu oni se samo navode i ukazuje se na to šta su podrazumevali.

Čas gimnastike obuhvatao je telesne vežbe za decu i mlade; držala ih je Smilja Mandukić, a, pored sadržaja radijskog programa, dosatne slike vežbi davane su u časopisu Radio Beograd. Dakle, časopis Radio Beograd bio je povremeno slikovna podrška vežbama prezentovanim na Radiju. Ovi časovi emitovani su u periodu 1931-1936 i nekoliko puta 1939. godine. Smilja Mandukić bila je istaknuta balerina, pedagškinja, koreografkinja i jedna od pokretačica savremene igre u Srbiji. Časovi gimnastike za decu podsticali su ih da budu fizički aktivna i da razvijaju svoje telo; akcenat je stavljen na zdravlje dece i mladih i na njihov fizički razvoj. S obzirom da nije bilo mogućnosti za slušanje časa gimnastike na radiju, posebna pažnja tokom istraživanja posvećena je prilozima u časopisu. U brojevima časopisa u kojima ima slika vežbi uočeno je da su vežbe jasno prikazane, da su deca mogla samostalno da ih prate uz slušanje govora na radiju, da su vežbe, pre svega, bile raznovrsne i obuhvatale različite grupe mišića za vežbanje. Uporedo sa slikama nema pisanog uputstva kako se rade vežbe, nedostaje broj ponavljanja vežbi, kao i 
ukazivanje na specifičnosti nekih vežbi i obraćanje pažnje na moguće opasnost od povreda prilikom izvođenja vežbi. Radio je ukazivao na važnost vežbanja za zdrav život i normalan razvoj dece. Dakle, urednici radijskog programa obuhvatili su i ovaj segment razvoja dece i mladih.

Kategorijom programa za decu i mlade obuhvaćeni su i časovi podmlatka Crvenog krsta, takođe emitovani na Radio Beogradu. Čas podmlatka Crvenog krsta predstavljao je jedan od načina da se animiraju deca da aktivno učestvuju u humanitarnom radu širenjem znanja o vrednostima koje zastupa Crveni krst i promocijom solidarnosti. Ovi časovi realizovani su na programu Radio Beograda jednom godišnje od 1934. do 1938. Čas je obuhvatao različite teme iz oblasti rada Crvenog krsta kao što su ukazivanje prve pomoći, promocija zdravih životnih navika, širenje znanja o vrednostima koje promoviše i zastupa Crveni krst. Uviđa se da su i urednici radijskog programa shvatili važnost Crvenog krsta kao važne humanitarne organizacije, te vaspitno-obrazovne aktivnosti koje je realizovala. Uvideli su i potencijale učenja dece osnovnim principima rada ove organizacije kao promotera nekih od osnovnih vrednosti društva, pre svega - humanosti.

Analizirajući program za decu i mlade, može se uvideti da su urednici radijskog programa posvetili pažnju deci i mladima i omogućili im da imaju prostor i vreme u jednom masovnom mediju kao što je radio. Bogat sadržaj omogućavao je najmlađim slušaocima različite emisije koje su mogli da prate $u$ skladu sa svojim željama i interesovanjima. Ovde se otvorilo pitanje: kakva je bila slika deteta u medijima? Iako se govori o počecima radija kao masovnog medija u Kraljevini Jugoslaviji, značajno je to što se u tom početnom razvoju medija počinje razvijati određena predstava o detetu. Otvaranjem vrata radio stanice deci, pružena im je mogućnost da slobodno izraze svoje mišljenje, da 
otvaraju teme koje su njima relevantne, kao i da doprinesu razvoju daljeg programa svojim učešćem.

\section{Vaspitno-obrazovna funkcija predavanja na radiju}

Predavanja na radiju predstavljaju jednu od kategorija koja se javila u okviru vaspitno-obrazovnog sadržaja programa Radio Beograda. Jedan su vid neformalnog obrazovanja za slušaoce, dakle, to je model obrazovanja koji se odvija van ustanova vaspitanja i obrazovanja koje obezbeđuje formalno izraženo sticanje znanja (Antonijević, 2013). Analizirajući obiman materijal koji je obuhvatao radijske programe koji se nalaze u časopisu Radio Beograd, prebrojavanjem je utvrđeno da je u periodu od 1929. do 1940. bilo ukupno 3669 predavanja. S obzirom na veliki broj predavanja tokom analize programa, formirane su oblasti koja se prema tematici mogu razvrstati po kategorijama koje su grafički prikazane.

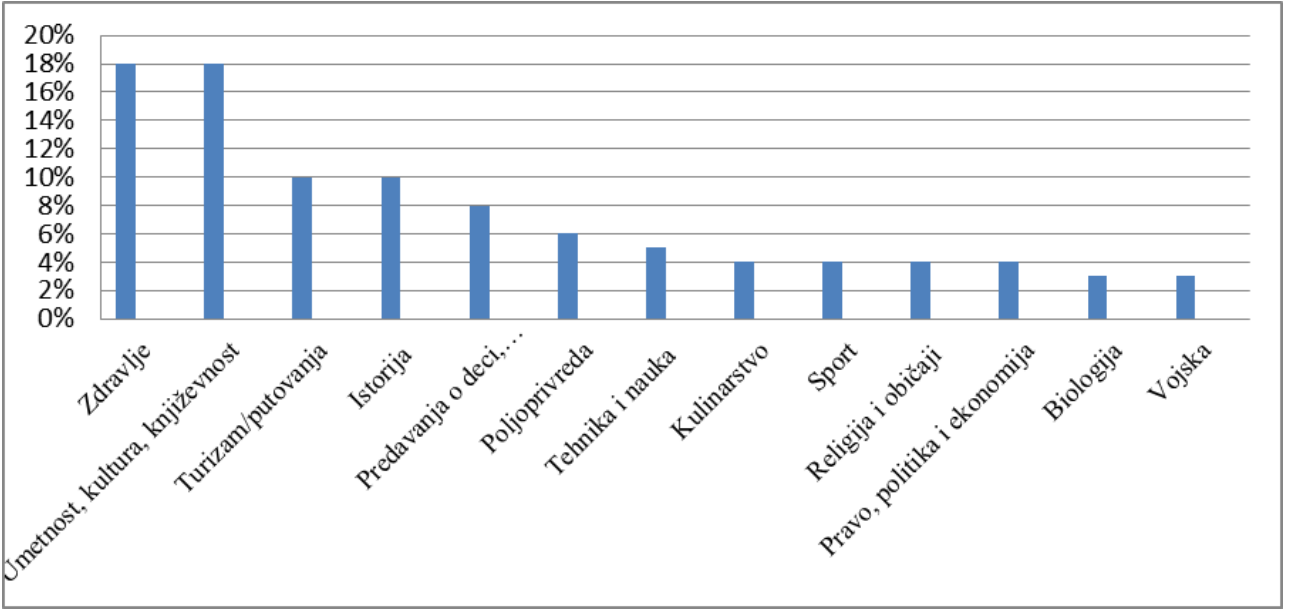

Grafikon 4. Prikaz predavanja na Radio Beogradu u periodu od 1929. do 1940. godine 
Uočava se da su najzastupljenije (18\%) dve kategorije: zdravlje i umetnost/književnost/kultura. Najniži procenat zastupljenosti (3\%) imala su predavanja iz oblasti veterine, biologije i vojske. Posebna pažnja u ovom radu posvećena je oblasti pod nazivom predavanja o deci, roditeljima, vaspitanju i obrazovanju. U periodu od 1929. do 1940. na Radio Beogradu emitovano je ukupno 288 predavanja iz ove oblasti. Grafikon pokazuje da su ova predavanja zastupljena procentom od $9 \%$.

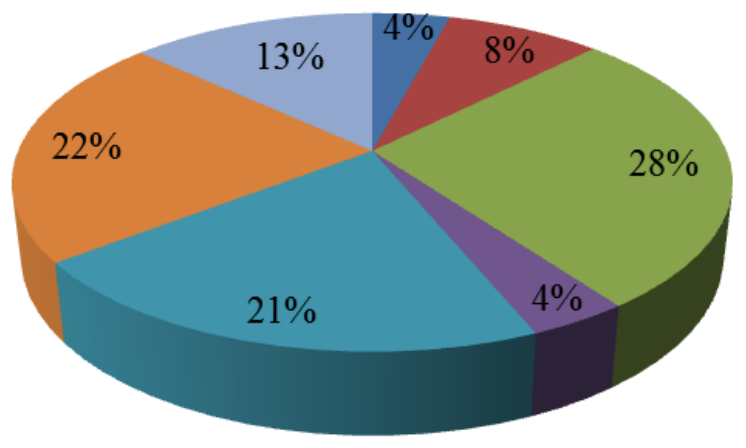

- Sport za decu i mlade

- Književnost za decu

- Saveti o postupanju sa decom

-Ustanove za decu

- Zdravlje i zaštita dece i mladih

ఐ Škola i učenje

- Roditelji i deca

Grafikon 5. Predavanja o deci, roditeljima, vaspitanju i obrazovanju

Predavanja od deci, roditeljima, vaspitanju i obrazovanju obuhvataju ukupno 7 tema, u okviru kojih su i podeljena. Tema pod nazivom ,saveti o postupanju sa decom“ najčešća je i iznosi $28 \%$.

Predavanja o ovoj temi značajna su jer su roditeljima pružala praktične savete za brigu i negu dece, posebno ako su ta predavanja držali pedagozi ili druge osobe koje su imale znanja i iskustva u radu sa decom. Zahvaljujući ovim savetima, roditelji su mogli da unaprede svoje vaspitne kompetencije. Tokom istraživanja radijskog programa nismo naišli na 
informaciju o osobama koje su davale savete. Tema pod nazivom „škola i učenje“ obuhvatala je predavanja koja su govorila o školi kao vaspitnoobrazovnoj ustanovi, o učiteljima, učenicima, procesu učenja, teškoćama sa kojima su se susretali učenici. Zastupljenost ove teme predavanja iznosi 22\%. Tema „zdravlje i zaštita dece i mladih“ ima zastupljenost $21 \%$. Pretpostavlja se da su roditelji slušajući ova predavanja na radiju mogli da nauče koje su sve bolesti postojale kod dece, kako su se te bolesti lečile, koji su simptomi postojali kod dece a koji su ukazivali na neke od bolesti kao i važnost njihovog lečenja čim su bile otkrivene. U programskoj shemi nalazi se podatak da su ova predavanja držali specijalisti iz različitih oblasti medicine. Tema naslovljena „Roditelji i deca“ zastupljena je 13\%; u programskoj šemi Radija nalaze se samo naslovi ovih predavanja, bez informacija o tome ko ih je držao. Zastupljenost teme „Književnost za decu“ iznosi 8\%. Postojanje određenog broja predavanja koja su razmatrala dečiju literaturu, pesme za decu, koja su ukazivala na kvalitetne knjige za decu, potvrđuje ono što je već napomenuto, a to je da unose inovacije u dečiju literaturu i da se knjige koriste kao vaspitno-obrazovno sredstvo sve više i sve češće. Grafikon ukazuje da na dve teme predavanja sa istim procentom zastupljenosti (4\%): jedna je „sport za decu“ a druga ,ustanove za decu“.

\section{"Nacionalni čas"}

Emisija "Nacionalni čas" pripada programu vaspitno-obrazovnog sadržaja. Na grafičkom prikazu 3 vidi se da zastupljenost ove emisije iznosi 23\%. Ovde je bitan "Nacionalni čas" zbog naglašenog značaja koje mu je dato u to vreme i zbog ideološkog i političkog značenja koje je imao. U radijskom programu "Nacionalni čas" bio je izdvojen kao posebna vaspitnoobrazovna emisija. "Nacionalni čas" je imao veliku popularnost među 
radijskom publikom i predstavljao je sredstvo za ostvarivanje političkih ciljeva vladajuće ideologije.

Ipak, važno je praviti razliku između manipulacije, indoktrinacije, s jedne, i vaspitanja i obrazovanja, s druge strane. Manipulacija podrazumeva umešnost ili spretnost zavođenja, dok indoktrinacija predstavlja efikasnu formu zarobljavanja i svođenja čoveka od autonomnog subjekta na jedinku kojom se manipuliše u željenom smislu (Mišković, 2016:15). U procesu vaspitanja, manipulacija je $\mathrm{u}$ tesnoj vezi sa socijalizacijom, naročito sa političkom socijalizacijom i shvatanjem autoriteta (Mišković, 2016:16). Zato se postavlja pitanje kakav je autoritet odrasle osobe (vaspitača, učitelja, nastavnika) u vaspitnom procesu potreban? Svaka ideologija teži hegemoniji, dominaciji, vladanju, reprodukciji i legitimaciji, a najbolje mogućnosti za to pružala je škola (Todorović, 2015:49-50), pre svega vaspitno-obrazovni proces, a sa razvojem medija i upotreba radija.

Tokom vladavine Milana Stojadinovića od 1935. do 1939, primetna je upotreba masovnih medija u političke svrhe a radi ostvarivanja političkih ciljeva. „Novi masovi mediji, posebno radio, film, plakati i leci služili su tome da u dobrom svetlu predstave dinastiju i vladu, i da ulepšaju sliku Jugoslavije u svetu" (Čalić, 2013:151). Pretpostavlja se da su autori "Nacionalnog časa" hteli da ovim nazivom istaknu pre svega njegovu obrazovnu funkciju, jer reč ,čas“ kao strukturna komponenta u sebi objedinjuje cilj i zadatke određenog rada. Da li je "Nacionalni čas" imao informacijsku funkciju s obzirom da se u to vreme vodilo računa o informacijama koje će biti emitovane slušaocima? Čini se da vaspitanje i obrazovanje kao procesi ne mogu da budu vrednosno neutralni, ne mogu se izdvajati od društveno-političkog, ideološkog, normativnog i kulturnog konteksta u kojem se realizuju. Savremeni autori govore o 
dezideologizaciji koja označava na neki način oslobođenje, ili kraj jedne idologije. Međutim, neosnovano je govoriti o takvom procesu jer škola, kao i masovni mediji, predstavlja deo društva, tj. deo sistema iz kojeg proizilazi njegova osnovna funkcija kao deo vaspitne funkcije društva $u$ celini (Todorović, 2015:49).

Tokom analize emisije "Nacionalni čas" javio se veliki broj pitanja. Pre svega, da li je bilo potrebno da se "Nacionalni čas" izdvaja kao poseban sadržaj radijskog programa? Ko je činio grupu urednika ove emisije? Koji su bili kriterijumi za izbor sadržaja emisije? Šta su najmlađi slušaoci mogli da nauče iz ove emisije što bi im pomoglo da se razviju kao autonomne, samopouzdane i celovite ličnosti? Pitanja ostaju otvorena za dalja istraživanja i diskusiju jer su svakako važna, posebno kada se razmatra da li u određenim vaspitno-obrazovnim sadržajima ima elemenata indoktrinacije.

\section{Časovi jezika i čas centrale za radničko vaspitanje}

Kao što se vidi na Grafikonu 3, časovi jezika zastupljeni su $13 \%$ u ukupnom programu sa vaspitno-obrazovnim sadržajem. Časovi jezika obuhvatali su sledeće časove: nemačkog, francuskog, engleskog, češkog i srpskog jezika. U okviru časova jezika emitovana su predavanja na stranim jezicima koja su imala funkciju da slušaoci bolje savladaju jezik i nauče nove reči. Primećeno je da su časovi jezika imali podršku i u časopisu Radio Beograd. Urednici časopisa su u godinama kada su časovi jezika bili emitovani na radio stanici (u periodu 1929-1938) pružali podršku tako što su objavljivali vežbe za učenje jezika. Na osnovu analize priloga u časopisu Radio Beograd, uočeno je da su vežbe jasno napisane, da su autori vežbi isticali koje je predavanje u pitanju i broj časa kako bi se lakše pratilo učenje jezika na radiju. 
I časovi jezika bili su jedan od načina da se realizuje zadatak narodnog prosvećivanja. Ovde se vidi jedna od od funkcija medija, pre svega obrazovna funkcija, jer se radio kao masovni medij koristi za učenje stranih jezika. Pored ove funkcije, primetna je i funkcija pod nazivom integracija. Radio kao medij na mnoge načine spaja ljude, kulturu, ideje (Jurčić, 2017:130), a učenjem stranih jezika slušaoci su mogli da komuniciraju sa ljudima iz inostranstva, da upoznaju nove kulture, običaje, način života i sl.

Tokom analize vežbi u časopisu Radio Beograd, može se zaključiti da ne postoje ikonička sredstva izražavanja (slike, crteži, fotografije, dijagrami), nema vizuelnog predstavljanja gradiva. Ikonička sredstva izražavanja su važna jer bi njihovim korišćenjem slušaocima koji uče jezik omogućila lakše usvajanje novog jezika, privukle bi pažnju čitalaca, pojasnila bi određene segmente gradiva i olakšala proces učenja novog jezika. Ipak, ne postoje nikakvi drugi vizuelni prikazi sem tabela koje su pregledne, jasne i strukturisane od jednostavnih ka složenijim. Časovi jezika su ukinuti 1938. godine na osnovu rezultata ankete zbog vrlo male zainteresovanosti (Bulatović i saradnici, 1979:18).

$\mathrm{Na}$ ovom mestu dobro je navesti i prenose sa Univerziteta i čas Centrale za radničko vaspitanje. Prenosi sa Univerziteta emitovani su retko, i to u prvim godinama emitovanja programa; podrazumevali su prenose predavanja ili određenih dešavanja (na primer: dodela nagrada, diploma, gostovanja i sl). Posle 1932. godine nisu se javljali u radijskom programu pod ovim nazivom, već su bili integrisani $u$ druge prenose koji su se preko radija emitovali $u$ državi. Čas Centrale za radničko vaspitanje emitovan je na programu tokom dve godine (1931/32). 
U okviru ovog časa emitovana su predavanja, recitacije, izvođenje numera, aktuelna pitanja u društvu i slično. Predavanja su mogla da doprinesu da slušaoci steknu nova znanja, pre svega iz oblasti vaspitanja dece. Ovde se uočava jedna od funkcija radija kao medija a to je prenošenje kulture. Pored navedene, identifikovane su i selekcijska i interpretacijska funkcija. Ove funkcije omogućavale su razvoj svesti o zajedničkim problemima i doprinosila koheziji zajednice (Juričić, 2017:131).

\section{ZAKLJUČAK}

Središte ovog rad su vaspitno-obrazovne funkcije koje je radio imao u periodu od 1929. do 1940. u Kraljevini Jugoslaviji. Cilj je utvrđivanje vaspitno-obrazovne funkcije radija kao sredstva masovnih medija u navedem periodu.

Tokom analize radijskog programa poseban značaj imala je kategorija program za decu i mlade koja je značajna iz više razloga. Pre svega, emisije koje se nalaze u okviru programa za decu i mlade predstavljaju same početke radijskog programa za decu u Kraljevini Jugoslaviji. Zahvaljujući raznovrsnom i bogatom sadržaju koji je emitovan, deca su shvaćena kao važna ciljna grupa urednika radijskog programa. Sadržaji namenjeni deci i mladima uvažavali su dečije potrebe, interesovanja, uzrast i druge razlike koje su postojale među najmlađim slušaocima radija. Važno je i pojava dečije književnosti, odnosno bajki za decu koje su emitovane na radiju. Posebnu pažnju posvećena je predavanjima o deci, roditeljima, vaspitanju i obrazovanju. Navedena predavanja značajna su jer su pružala roditeljima savete i uputstva o zdravlju, nezi i zaštiti dece, ukazivala su na odnos roditelja i deteta, škole i dece i razne druge teme. Zahvaljujući navedenim predavanjima, kao i savetima koje su 
mogli da čuju, roditeljima je omogućeno da unaprede svoje roditeljske kompetencije i da čuju veliki broj informacija o vapitanju i obrazovanju.

"Nacionalni čas", definisan kao emisija vaspitno-obrazovnog karaktera, otvorio je pitanje odnosa vaspitanja i obrazovanja i manipulacije i indoktrinacije. Takođe, "Nacionalni čas" definisan kao emisija koja je emitovana na radiju. otvorio je temu koja razmatra ulogu ideologije u vaspitnoobrazovnom procesu i koliko jedna ideologija može da bude štetna za jedno društvo.

Uzimajući u obzir rezultate navedene analize, može se reći da je Radio Beograd zastupao koncepciju nove pedagogije ${ }^{2}$. „U prvim decenijima posle rata "novo vaspitanje" predstavljalo je "tačku ukrštanja državnih interesa i novih naučnih saznanja o detetu i društvu“, dok je suština obrazovnog procesa podrazumevala obezbeđivanje uslova za detetov razvoj i podsticanje deteta da izrazi svoje potencijale (Ilić Rajković, 2013:118). „Zastupnike ovog koncepta povezivao je pedagoški optimizam - stanovište o vaspitanju kao sredstvu kojim se može obezbediti budućnost bez ratnih razaranja i demokratsko društvo, koje je projektovano kao nova era" (Ilić Rajković, 2013:379). Uverenje je da je pedagoška klima bila veoma otvorena prema inovacijama, posebno prema radiju kao sredstvu masovnih medija i vaspitno-obrazovnom sredstvu. Posebna pažnja bila je posvećena detetu kao važnom članu društva koje je imalo šta da kaže odraslima i na taj način učestvuje u društvu.

\footnotetext{
${ }^{2}$ Pokret za novo vaspitanje razvija se u godinama između dva svetska rata i bio je predmet razmatranja više savremenih autora. Oni konstatuju da je pojam „novo vaspitanje“ širok i da se odnosio na više koncepcija i realizovanih modela koji su bili razvijeni u svetu krajem XIX i u prvim decenijama XX veka (prema Ilić Rajković, 2013:118).
} 
Ovim istraživanjem obuhvaćen je samo jedan mali deo proučavanja istorijskog razvoja medija u našoj zemlji. Istraživanja istorijskog razvoja medija (u ovom radu radija) i vaspitno-obrazovnog procesa značajno je iz razloga što, ukoliko upoznamo kako su mediji korišćeni u vaspitanju i obrazovanju tokom istorije, možemo doći do saznanja i do otkrivanja novih načina za upotrebu medija u vaspitno-obrazovnom procesu.

\section{PEDAGOGICAL-EDUCATIONAL FUNCTION OF THE RADIO IN THE PERIOD FROM 1929 TO 1940 IN THE KINGDOM OF YUGOSLAVIA}

\section{Abstract}

The radio was the first electronic medium of mass communications which structure, in a technical-technological sense, was formed in the first decades of the 20th century, and which formation created conditions for massive distribution of audio messages in shaped radio programs. Certainly, the most important names that contributed to the development of the radio are Nikola Tesla, Guglielmo Marconi, Lee De Forest, and other researchers. The development of mass communication media has led to major and lasting changes in culture that have been reflected in changes in education as well. As pedagogues, we are aware of the power of media, and that the media are those which have significantly changed the behavior of children and parents in relation to earlier generations. The period from 1929 to 1940 is a period in which the development of the radio as a mass media experienced its expansion, both in the world and in the Kingdom of Yugoslavia, where the radio program was launched in Belgrade on March 24, 1929,. In this paper, we present the results of the analysis of the extensive program content that was broadcasted on Radio Belgrade in the Kingdom of Yugoslavia in the period from 1929 to 1940. In addition to the abovementioned, we paid a special attention to determining the pedagogical-educational functions of the radio in the mentioned period.

Key words: pedagogical-educational function, Radio Belgrade, Kingdom of Yugoslavia, program for children and youth, National Class. 


\section{REFERENCE}

Antonijević, R. (2013). Opšta pedagogija. Beograd: Institut za pedagogiju i andragogiju.

Boarov, D. i V. Barović (2011). Velikani srpske štampe. Beograd: Službeni glasnik.

Bulatović, M. i saradnici (1979). Ovde Radio-Beograd. Beograd: Radio Beograd.

Čalić, M. Ž. (2013). Istorija Jugoslavije u 20. veku. Beograd: Klio.

Graša, V. (2016). Bajka u predškolskom odgoju (završni rad). Pula: Fakultet za odgojne i obrazovne znanosti.

Haworth, M. \& Hopkins, S. (2009). On the air: educational radio, its history and effect on literacy, and educational technology implementation. Preuzeto: 18.11.2017.godine sa sajta: http://blogs.ubc.ca/etec 540sept09/2009/10/28/on-the-air-educational-radio-its history-andeffect-on-literacy-and-educational-technology-by-michael-haworthtephanie-hopkins/

Ilić Rajković (2013). Radna škola u Srbiji (1880-1940) (doktorska disertacija). Beograd: Filozofski fakultet Univerziteta u Beogradu.

Jurčić, D. (2017). Teorijske postavke o medijima-definicije, funkcije i utjecaj. Mostariensia, god. 21, str. 127-136.

Maričić, N. (2007). Producentski radio ili novinarski radio. U N. Maričić (ur.), Anatomija radija (str. 167-180). Beograd: Fakultet dramskih umetnosti.

Mišković, M. (2016). Proces i uloga poltičke socijalizacije u ranom detinjstvu. Krugovi detinjstva, br. 1, 12-31.

Poter, Dž. (2011). Medijska pismenost. Beograd: Klio.

Pravilnik o emisionim programima radio-stanica u Kraljevini Jugoslaviji (1933). Prosvetni glasnik Ministarstva prosvete, god. 49, br. 4, str. 357-358.

Radio Beograd časopis (1929-1940. godine)

Stojanović Đorđević, T. i V. Ilić (2017). Značaj igre, umetnosti i terapeutskih bajki u jačanju ličnosti deteta. Kragujevac: Filološko-umetnički fakultet. 
Todorović, M. (2015) Ideologija i položaj nastavnika u obrazovanju. International journal KNOWLEDGE. Vol. 11/2, 46-50.

Trebješanin, Ž. (2013). Pedagoška vrednost bajki-mišljenje roditelja koliko i zašto savremena deca vole bajke. U S. Denić (ur.), Književnost za decu i njena uloga u vaspitanju i obrazovanju dece školskog uzrasta (str. 28-38). Vranje: Učiteljski fakultet.

Vesić, I. (2016). Nastava muzike u Jugoslovenskim osnovnim i srednjim školama u period između dva svetska rata: osvrt na stručne, pedagoške i sociopolitičke dimenzije. U S. Marinković (ur), Tradicija kao inspiracija (str. 634-647). Banja Luka: Ministarstvo nauke i tehnologije Vlade Republike Srpske.

Vesić, I. (2013). Radio Belgrade in the process of creating symbolic boundaries: the case od folk music program between the two World wars (1929-1940). Muzikologija. Beograd: Institut za muzikologiju. 